- ACORN Australan college of | JOURNAL OF PERIOPERATIVE NURSING

Volume 34 | Issue 2

Article 1

4-19-2021

\title{
Multidisciplinary simulation training for perioperative teams: An integrative review
}

Follow this and additional works at: https://www.journal.acorn.org.au/jpn

Part of the Perioperative, Operating Room and Surgical Nursing Commons

(c) (i)

This work is licensed under a Creative Commons Attribution 4.0 License.

\section{Recommended Citation}

Hibberson, Michelle; Lawton, Jessica; and Whitehead, Dean (2021) "Multidisciplinary simulation training for perioperative teams: An integrative review," Journal of Perioperative Nursing: Vol. 34 : Iss. 2 , Article 1. Available at: https://doi.org/10.26550/2209-1092.1111

https://www.journal.acorn.org.au/jpn/vol34/iss2/1

This Article is brought to you for free and open access by Journal of Perioperative Nursing. It has been accepted for inclusion in Journal of Perioperative Nursing by an authorized editor of Journal of Perioperative Nursing. 


\section{Authors}

Michelle Hibberson

MCN (Anaes \& PACU), BN, RN, MACORN,

MACPAN

University of Tasmania

Jessica Lawton

MCN, BN (Hons), RN

Senior Lecturer, College of Health and

Medicine, University of Tasmania

Dr Dean Whitehead

PhD, MSc, MPH, BEd, FCNA(NZ)

Senior Lecturer, College of Health and

Medicine, University of Tasmania

\section{Corresponding author}

Michelle Hibberson

MCN (Anaes \& PACU), BN, RN, MACORN,

MACPAN

tmhibbo@gmail.com

\section{Multidisciplinary simulation training for perioperative teams: An integrative review}

\section{Abstract}

\section{Background}

The perioperative environment is a high-risk and complex area and the provision of safe, high-quality surgical care requires a multifaceted approach provided by multidisciplinary health care teams. However, it is reported that the multidisciplinary nature of perioperative teams can present barriers to patient safety through ineffective teamwork, ineffective collaboration and/ or ineffective communication. Multidisciplinary simulation training creates realistic situations in safe environments to allow perioperative teams to improve teamwork and communication alongside the technical skills needed to manage emergency situations. This integrative review critically examines and reports the effects of multidisciplinary simulation training on perioperative teams and highlights the actual and potential advantages and disadvantages of such training.

\section{Method}

A structured integrative literature review process was undertaken yielding 14 key articles that were critically appraised and examined for emergent 'themes'.

\section{Results}

Multidisciplinary simulation training improved communication, teamwork, teamwork behaviours and teamwork attitudes between multidisciplinary perioperative team members. Overall, improvements in communication and teamwork correlated with improvements in perioperative patient safety. Despite the numerous benefits of multidisciplinary simulation training there are notable barriers to the implementation of such training programs. Multidisciplinary simulation training can be costly to set up and time consuming to facilitate. However, overall increases in patient safety offset the cost of simulation training and time-based barriers can be reduced by running simulation training in conjunction with existing education programs.

\section{Conclusion}

Multidisciplinary simulation training improved communication and teamwork among perioperative teams and this method of training is recommended overall within perioperative units. However, there were notable gaps within the literature, and further research involving multidisciplinary perioperative teams within Australian perioperative units should be conducted to gain a greater insight into the presence of multidisciplinary simulation training and the effects of such training.

Keywords: simulation training, multidisciplinary, interprofessional, interdisciplinary, perioperative, operating room, theatre 


\section{Introduction}

Perioperative services are an essential part of health care, providing optimal health outcomes for patients through surgical and diagnostic procedures ${ }^{1,2}$. Perioperative care can be a high-risk and complex process and the provision of safe, high-quality surgical care requires a multifaceted approach provided by multidisciplinary health care teams ${ }^{3-5}$. Multidisciplinary perioperative teams consist of nurses, surgeons, anaesthetists and, depending on patient needs, may involve other health care professionals $3,6,7$. During all stages of perioperative care, multidisciplinary teams are expected to work interdependently and collaboratively to meet the needs of the patient ${ }^{3}$. However, the multidisciplinary nature of perioperative teams can present specific barriers to patient safety mainly through ineffective teamwork, collaboration and/or communication?. In perioperative emergency situations ineffective teamwork, collaboration and communication increases the likelihood of adverse health outcomes for the perioperative patient ${ }^{9,10}$. Multidisciplinary simulation training has been identified as a method of training which can improve teamwork and communication within perioperative teams ${ }^{4,11}$. The origins of simulation training can be traced back to the aviation industry, for the same reasons that it has been adopted in health care, and it is interesting to note that anaesthetists were the early adopters of this method of training ${ }^{12,13}$. Simulated scenarios, often based on perioperative emergencies, are widely needed to allow the multidisciplinary perioperative team to learn, practice and improve the technical and non-technical skill required to manage perioperative emergencies ${ }^{14}$. With this in mind, the aim of this paper is to explore the effectiveness of simulation training for multidisciplinary perioperative teams and identify potential gaps in practice through undertaking an integrative review of the research literature examining multidisciplinary simulation training in the perioperative setting.

\section{Background}

\section{Multidisciplinary teams}

Multidisciplinary perioperative teams consist of professionals from multiple disciplines such as surgeons, anaesthetists, anaesthetic technicians, theatre technicians and nurses ${ }^{3,6}$. Unfortunately, the multidisciplinary nature of perioperative teams can present barriers to safe patient care, as a result of disciplinary 'silos', hierarchy and professional rivalries ${ }^{4,7,15}$. These barriers are confounded by differences in clinical expertise, individual experiences and differing priorities for care ${ }^{9}$. Additionally, individual team members are continually changing due to rostering and transient workforces ${ }^{6,9}$. All of these factors combined reduce team effectiveness and perioperative patient safety ${ }^{9}$.

\section{Multidisciplinary simulation training}

Multidisciplinary simulation training is a teaching technique whereby scenarios are created to represent realistic clinical situations to allow professionals to practice, learn, test or evaluate human actions, physical systems and processes ${ }^{6}$. Simulated scenarios are developed from relatively uncommon emergency events allowing perioperative teams to learn how to manage these events without causing harm to patients $4,4,16,17$. Simulation training may occur within the environment in which the perioperative team would normally work or be conducted in dedicated simulation centres ${ }^{18}$. However, for learning to be effective the environment in which simulation training takes place needs to reflect the clinical environment to provide participants with realistic and dynamic feedback ${ }^{19-21}$.

\section{Non-technical and technical skills}

Perioperative care requires the use of both non-technical and technical skills to facilitate safe patient care, and failures in either have been associated with sentinel events within health care ${ }^{1,11}$. Non-technical skills encompass interpersonal and cognitive aspects such as teamwork, collaboration, situational awareness, decision-making, problem-solving, task management, leadership and communication ${ }^{7,0,17,22,23}$. Technical skills relate to the physical motor skills required to perform specific clinical tasks, for example, performing a surgical procedure or inserting an endotracheal tube ${ }^{12,17}$. Technical skills also refer to the clinical knowledge needed to perform specific tasks related to patient care ${ }^{12,17}$. Simulation training provides a platform in which technical skills rarely used in clinical practice can be practiced without causing patient harm ${ }^{12,17}$.

Teamwork and communication are the non-technical skills focused on predominantly during multidisciplinary simulation training ${ }^{21}$ Effective communication within perioperative multidisciplinary teams is essential for collaboration, task management, leadership and teamwork ${ }^{10,15,24,25}$. Social dynamics, heightened emotions in stressful situations and unclear messages all cause ineffective communication within multidisciplinary perioperative teams ${ }^{7,26}$. This can be confounded by differences in communication training between the different disciplines within health care ${ }^{10,27}$. Teamwork requires multidisciplinary 
perioperative team members to work dynamically, interdependently and collaboratively while undertaking specific roles to achieve shared goals ${ }^{7,22,28}$. All non-technical skills are interrelated, and inadequate levels of non-technical skills within multidisciplinary perioperative teams pose a significant risk to patient safety ${ }^{1,11}$.

\section{Methods}

\section{Integrative review}

A systematic process was used to conduct a detailed search of databases to identify current research literature related to perioperative simulation training. The review was integrative in that it drew upon, compared and contrasted both qualitative and quantitative studies (no mixed method studies were reported) to provide insight into multidisciplinary simulation training through the identification, summary and critique of themes 29,30 .

\section{Databases}

To conduct a critical appraisal of the literature, a systematic search of the following electronic databases was conducted ${ }^{30-32}$. Databases were searched with a linear approach beginning with PubMed, EBSCOhost and lastly Ovid. EBSCOhost was used to search CINAHL, Academic Search Ultimate, Australian/ New Zealand Reference Centre Plus, Health Source: Nursing/Academic Edition, Medline and Medline Complete. Ovid was used to search UTAS Journal@Ovid, Joanna Briggs Institute EBP Database, Embase, Ovid Emcare and Ovid Medline all.

\section{Key terms}

To ensure a focused search of the literature, key terms were drawn from the research topic using the University of Tasmania's

Table 1: Concept table

\begin{tabular}{|c|c|c|c|c|}
\hline Group One & \multirow{6}{*}{ AND } & Group Two & \multirow{6}{*}{ AND } & Group Three \\
\hline \multirow[t]{5}{*}{$\begin{array}{c}\text { simulation } \\
\text { training }\end{array}$} & & multidisciplinary & & peri*operative \\
\hline & & OR & & OR \\
\hline & & interdisciplinary & & operating room \\
\hline & & OR & & OR \\
\hline & & interprofessional & & theatre \\
\hline
\end{tabular}

concept table template. The key terms 'simulation training', 'multidisciplinary', 'interprofessional’, 'interdisciplinary', 'perioperative', 'operating room' and 'theatre' were divided into three groups (Table 1). The asterisk truncation symbol was applied to retrieve all variables of the key term 'perioperative ${ }^{30}$. Additionally, the following Medical Subject Headings (MeSH) terms were exploded and combined with major concepts within PubMed and Ovid ${ }^{30}$. 'Interdisciplinary studies', 'simulation training' and 'operating rooms' MeSH terms were exploded and combined with major concepts within PubMed. 'Simulation training', 'high fidelity simulation training', 'patient simulation' and 'operating room' were selected as MeSH terms

\section{Table 2: Inclusion criteria}

\begin{tabular}{|l|l|}
\hline Inclusion criteria & Exclusion criteria \\
\hline Simulation-based team training & $\begin{array}{l}\text { Simulation training conducted } \\
\text { in emergency departments and } \\
\text { intensive care units }\end{array}$ \\
\hline $\begin{array}{l}\text { Multidisciplinary team members } \\
\text { from anaesthetic, surgical and } \\
\text { perioperative nursing professions }\end{array}$ & $\begin{array}{l}\text { Simulation training involving animal } \\
\text { models, virtual reality and actors }\end{array}$ \\
\hline $\begin{array}{l}\text { Simulation-based training facilitated } \\
\text { in situ or off-site }\end{array}$ & Abstracts \\
\hline Full-text articles & $\begin{array}{l}\text { Literature, narrative and integrative } \\
\text { reviews }\end{array}$ \\
\hline Articles publish after 2010 & Historical papers \\
\hline Articles written in English & Editorials \\
\hline Primary research articles & \\
\hline
\end{tabular}

and major concepts within Ovid and exploded. Key terms and MeSH terms were combined within group one, two and three with the Boolean operator $\mathrm{OR}$, and each group were combined with the Boolean operator AND ${ }^{32}$.

Inclusion and exclusion criteria (Table 2) were set to focus the search strategy, producing literature closely aligned to the key terms ${ }^{30,32}$. Articles were accepted if they included simulation-based training for multidisciplinary perioperative teams consisting of nurses, anaesthetists, surgeons and/or students from any of those disciplines. The location of simulation training could occur

\section{Inclusion and exclusion criteria} . 


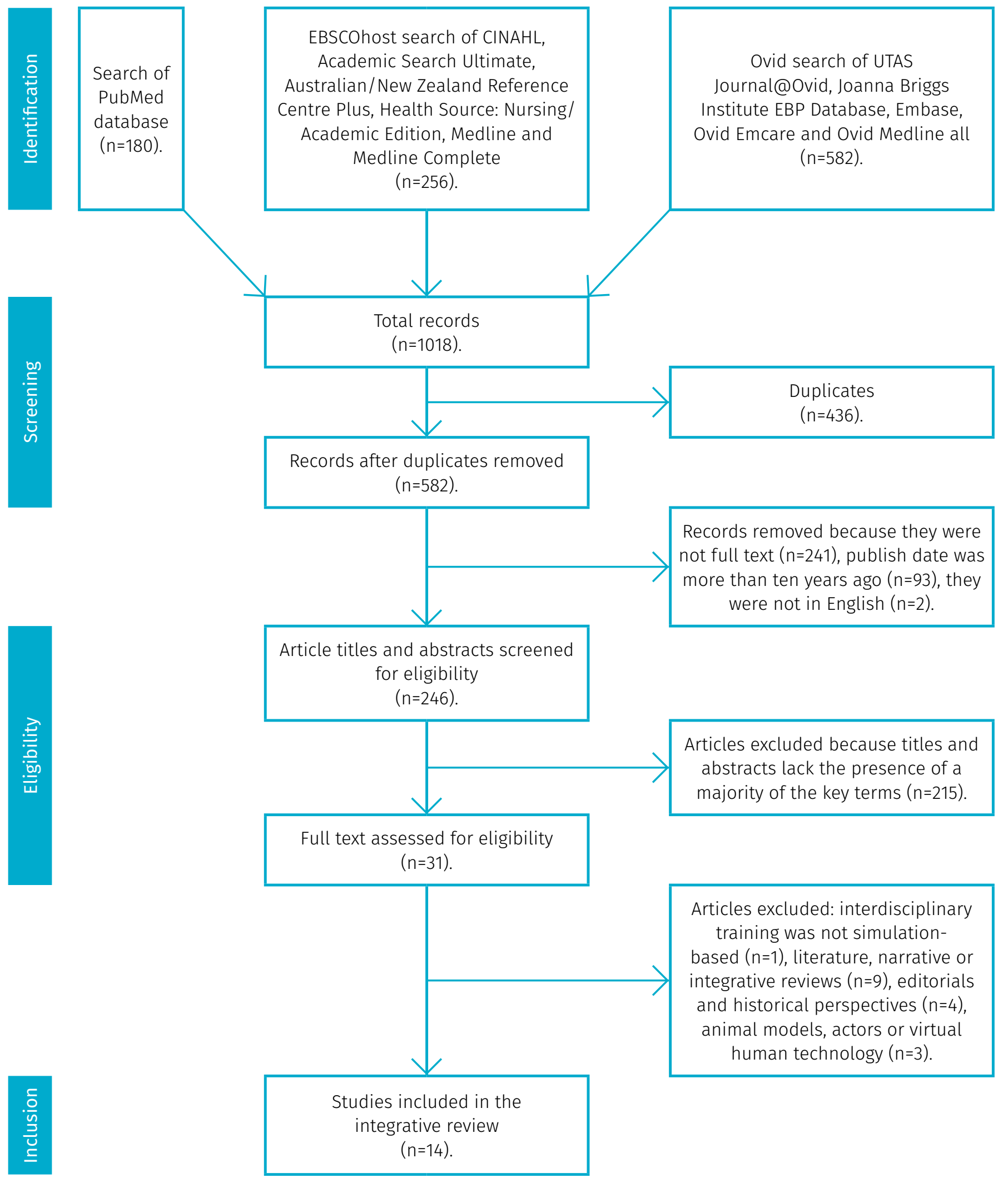

Figure 1: PRISMA flow diagram 
in situ or be conducted off-site provided the training location emulated the perioperative setting. Articles were included if they were less than ten years old, were full text, written in English and primary research. Articles were excluded if they were abstracts only, literature, narrative and integrative reviews or were historical papers and editorials. Articles were excluded if simulation training involved animal models, virtual simulation or used actors as members of the multidisciplinary team.

\section{Results}

The search results are presented in a PRISMA flow diagram (Figure 1). A total of 1018 records were obtained and reduced to 582 when duplicate studies were removed. A further 241 records were removed because they were not full text, 93 records removed because they were older than ten years and two records removed because they were not in English. The titles and the abstracts of the remaining 246 records were assessed to ensure the papers included some measure of multidisciplinary simulation training within the perioperative setting. A further 215 records were excluded, and the remaining 31 articles read in full. One article was excluded because the interdisciplinary training was not simulation-based and nine articles were excluded because they were literature, narrative or integrative reviews. Four articles were excluded because they were editorials and historical perspectives and a further three articles excluded because they involved animal models, actors or virtual human technology.

\section{Critical analysis}

\section{Quality appraisal}

To enhance the quality of this integrative review, the 14 studies chosen were assessed for quality, trustworthiness and relevance ${ }^{31-33}$. The JBI Checklist for quasi-experimental studies (nonrandomised experimental studies) ${ }^{34}$ was applied to the non-randomised quantitative and mixed-method studies (see supplemental material). The Joanna Briggs Institute (JBI) Checklist for qualitative research ${ }^{35}$ was applied to qualitative studies (see supplemental material). To calculate the percentage for the 14 chosen studies, each question within the relevant JBI checklist ${ }^{34,35}$ was assigned a score of one. Scores were totalled, divided by the number of questions in each tool and multiplied by 100 to calculate the percentage. Studies were considered to be of an appropriate quality if they scored 70 per cent or greater using the JBI checklists.

\section{Theme identification}

Critical analysis of the 14 primary studies required the identification of recurring and important themes and subthemes. Themes and subthemes were identified through an iterative approach involving reading and re-reading the primary studies, identifying themes and subthemes and determining the frequency with which these

\section{Table 3: Themes and subthemes}

\begin{tabular}{|l|l|}
\hline \multirow{2}{*}{ Themes } & Subthemes \\
\hline Teamwork & Debriefing \\
\cline { 2 - 2 } & Hierarchy and assertiveness \\
\hline Simulation fidelity & Non-technical skills \\
\hline Clinical change & $\begin{array}{l}\text { In situ simulation vs off-site } \\
\text { simulation }\end{array}$ \\
\cline { 2 - 2 } & Fidelity \\
\hline Barriers to program & Patient safety \\
\hline implementation & Cost \\
\cline { 2 - 2 } & Time \\
\hline
\end{tabular}

themes and subthemes appeared in the primary studies Checklist for quasi-experimental studies (nonrandomised experimental studies) ${ }^{36}$. The final list of recurrent and repetitive themes and subthemes are identified in Table 3. Each theme and subtheme are expanded on in the discussion to examine the effect of multidisciplinary simulation training on perioperative teams.

\section{Discussion}

Critical analysis of the studies included in this review identified five themes: communication, teamwork, simulation fidelity, clinical change and barriers to program implementation.

\section{Communication}

Effective communication between multidisciplinary perioperative team members during emergency events is vital for safe perioperative patient care ${ }^{9,25,37}$. Breakdowns in communication can be driven by professional hierarchies and lack of assertiveness, and is confounded by fatigue, interruptions and stressful high-risk situations?. Weller $^{38}$ identified that too much noise in the operating theatre also has a negative impact during 
emergency events. The disruptive effect of noise was also present in simulation training as S $\phi$ rensen ${ }^{39}$ identified that talking and laughing during simulation training reduced effective learning. Excessive noise needs to be reduced in perioperative environments as it distracts focus away from critical tasks and prevents effective communication between multidisciplinary perioperative team members $38,40,41$.

Overall communication between multidisciplinary perioperative team members increased following simulation training 38,39,42-45. Furthermore, after undertaking multidisciplinary simulation training, perioperative teams were able to identify specific strategies for improving communication during emergency events $s^{38,44,45}$. These strategies included using a whiteboard, avoiding acronyms and using common language to improve communication during an emergency ${ }^{38,44,45}$. Additionally, closed loop communication was identified as an effective communication strategy ${ }^{38,44-46}$. Closed loop communication creates a shared mental model through a process of information sharing, understanding and timely feedback ${ }^{37}$. Effective communication leads to effective teamwork as it enhances leadership and task management. All of which are important non-technical skills required by multidisciplinary perioperative teams to manage emergency events.

An additional strategy for improving communication between multidisciplinary perioperative teams was direct communication ${ }^{38,45}$. Direct communication involves using names to communicate directly with individual team members ${ }^{38,45}$. The Surgical Safety Checklist $^{47}$ requires perioperative team member's roles and names to be identified prior to the start of surgery.
However, multidisciplinary teams members may change throughout the surgical case and face masks reduce the ability to recognise team members ${ }^{48-50}$. Furthermore, only 30 per cent of names are recalled after team members are initially introduced ${ }^{48,49}$. Briefings at the beginning of the day have been identified as a method of increasing name recall ${ }^{45}$. Despite the issues just noted, simulation training is identified as an ideal way to 'get to know' the team members within the multidisciplinary team ${ }^{39,45,50}$. Multidisciplinary perioperative team members also highlighted their appreciation for the opportunity to work in set teams during simulation training as it increased familiarity between team members and would therefore make direct communication easier ${ }^{50}$. Effective communication leads to effective teamwork as it enhances leadership and task management. These are important non-technical skills required by multidisciplinary perioperative teams to manage emergency events.

\section{Debriefing}

An important forum for communication following multidisciplinary simulation training is debriefing after the simulation $n^{7,1,12}$. If multidisciplinary perioperative teams are to meet learning objectives through simulation training they must reflect on their experience and test their understanding of knowledge gained ${ }^{51}$. This process is undertaken during debriefing and leads to a higher level of retention of key learning objectives through reflection, analysis, discussion and feedback ${ }^{71,51}$. Multidisciplinary perioperative teams identified debriefing as the most positive and important part of learning following simulation training 39,52 . Debriefing facilitated identification of patient care issues and reinforced learning gained during simulation training, resulting in the transfer of new knowledge to the clinical setting 39,53 . Debriefing also provided multidisciplinary team members with the opportunity to destress following simulation training 51,52,54.

Given the multiple functions of debriefing it is imperative that debriefing is facilitated by trained and experience staff ${ }^{51,55}$. Properly facilitated debriefing sessions enable simulation participants to feel comfortable with being open and honest ${ }^{53}$. Furthermore, Shapiro ${ }^{46}$ emphasised the need for debriefing to be facilitated by staff who are aware of accreditation requirements as they used simulation training to ensure their office-based plastic surgery clinic met accreditation standards. This highlights the potential for multidisciplinary simulation training to be used to implement organisational changes to meet national standards and guidelines. However, accessing appropriately trained debriefing staff can be difficult and costly, presenting a potential barrier to the implementation of multidisciplinary simulation training 38,52 .

\section{Hierarchies and assertiveness}

Traditional hierarchies within perioperative teams prevent open communication and have negative impacts on patient outcomes ${ }^{14,56}$. Multidisciplinary team members identified the need to improve communication and teamwork and reduce hierarchies within the perioperative environment 45 . Comments made after the simulation, showed simulation training gave perioperative team members more confidence to 'speak up $^{\prime 44,45,53}$. Interestingly, nurses and anaesthetists were more likely to identify the need to speak up than surgeons, demonstrating the existence of traditional hierarchies 
within perioperative units ${ }^{53,57}$.

Although simulation training enabled multidisciplinary perioperative team members to feel more able to 'speak up', simulation training has not provided strategies for reducing professional hierarchies. In fact, reversing hierarchies by placing junior medical staff in leadership roles during simulation training has a negative impact on the experience of multidisciplinary simulation training ${ }^{39}$. Involving students who may pursue a career in the perioperative field has been identified as a potential way of reducing professional hierarchies 43,55 .

\section{Teamwork}

\section{Non-technical skills}

Effective teamwork among multidisciplinary perioperative teams requires individuals to work dynamically, interdependently and collaboratively while undertaking specific roles to achieve shared goals ${ }^{7,22,28}$. Overall, there were improvements in teamwork, teamwork behaviours and teamwork attitudes following multidisciplinary simulation training of perioperative

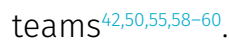

A range of rating systems were used to measure improvements in teamwork. Rating systems such as Behavioural Marker Risk Index (BMRI), Non-Technical Skills II (NOTECHS II), Non-Technical Skills for Surgeons (NOTSS) and Anaesthetist's Non-Technical Skills (ANTS) were used within the literature ${ }^{38,42,50,58}$. Each rating system indicated improvements in teamwork by assessing non-technical skills such as leadership, management, problem solving, teamwork, cooperation, decision making, situational awareness and task management ${ }^{50,58}$. Further to this, information sharing, briefing, contingency management, inquiry, assertion, inter-disciplinary information sharing and vigilance are assessed in the BMRI rating system $^{38,42}$.

Rochlen ${ }^{50}$ demonstrated overall improvements in NOTECHS II following simulation training. There were also improvements in NOTSS, ANTS and BMRI scores $38,42,58$. Rochlen $^{50}$ found leadership and management improved the most following multidisciplinary simulation training, and proposed that this occurred due to the focus on communication during the debriefing process. Interestingly, communication and information sharing were identified as the individual components of the BMRI score which improved significantly as a result of simulation training ${ }^{38}$. Further to this, debriefing was pivotal for multidisciplinary perioperative team members to identify the importance of information sharing ${ }^{38}$. It is apparent that improvements in teamwork overall are dependent on improvements in non-technical skills $^{38,42,50,58}$. This demonstrates that non-technical skills are closely interrelated - communication and teamwork are not individual factors and for perioperative teams to engage in effective teamwork they need to become proficient in a range of non-technical skills.

Effective teamwork between multidisciplinary perioperative team members requires individual disciplines to cooperate, work interdependently and collaboratively ${ }^{7,22,28}$. This is evident by improvements in NOTSS scores which correlated with improvements in ANTS score but only when the scenarios were related to surgical complications ${ }^{58}$. When the scenario was based on a difficult airway there were improvements in ANTS scores only ${ }^{58}$. The surgeons did not contribute as much to this scenario demonstrating that simulation training needs to be appropriate to participant roles for learning to be effective ${ }^{39,50}$. However, only one surgical speciality was represented, and further research would be needed to assess if different surgical specialities demonstrate increases in NOTSS during a difficult airway scenario ${ }^{58}$. Additionally, NOTSS and ANTS scores are representative of only two disciplines which make up a perioperative team. Further research would be required to examine if lessons learnt during simulation training involving one or two disciplines would transfer to the perioperative team as a whole.

Traditionally, multidisciplinary simulation training has not been taught at an undergraduate level, and it has been assumed that medical and nursing students will develop competence in communication and teamwork without formal training ${ }^{61}$. Unfortunately, this leads to the development of professional 'silos' and differences in communication training which creates ineffective communication between multidisciplinary team members ${ }^{710,27}$. Multidisciplinary simulation training is an effective method of instilling consistent and optimal teamwork behaviours and attitudes in perioperative undergraduate students, interns and registrars ${ }^{43,52,55,60}$. Instilling teamwork earlier in the careers of these students reduces professional hierarchies, increases collaboration between multidisciplinary teams and improves the overall culture thus fostering better communication and teamwork within multidisciplinary perioperative teams $43,52,55,60$.

\section{Simulation fidelity}

Simulation training uses scenarios based on real clinical situations to allow multidisciplinary perioperative teams to practice and improve the non-technical and technical skills required to manage emergency situations without causing patient harm $^{16}$. 


\section{Fidelity}

The fidelity of a simulated scenario refers to the realism of a scenario, that is, the degree to which the simulated scenario correctly represents clinical events ${ }^{20}$. Simulation fidelity is identified as an important aspect of multidisciplinary simulation training to gain active engagement from perioperative teams ${ }^{45,46,50}$. Greater engagement and 'buy in' from multidisciplinary teams occur once the perioperative team members determine that the scenarios are realistic and reflective of their clinical experiences ${ }^{45,46,50}$.

There are several factors which influence the fidelity of simulated scenarios. Although, Shapiro ${ }^{46}$, Rochlen ${ }^{50}$ and Long ${ }^{45}$ highlight the impact functional and psychological fidelity have on perioperative team members engagement with simulation training, physical fidelity is also important. Sørensen ${ }^{39}$ found if perioperative team members wore their normal uniforms and full-scale mannequins or actors were used as patients, simulation fidelity was increased. However, some efforts at creating realistic situations during simulation training can be detrimental. Multidisciplinary team members found lists of telephone numbers to be disruptive and negatively impacted on the simulation experience ${ }^{39}$. Maintaining traditional roles during simulation training was also deemed important for simulation fidelity ${ }^{39}$; however, this could be problematic when challenging traditional hierarchies while undertaking simulation-based training, especially if traditional hierarchies are tied to traditional roles.

\section{In situ vs off-site simulation}

A further aspect of fidelity for simulation training is the physical setting in which a simulated scenario takes place. Simulation training can be in situ simulation (ISS), which is facilitated within the perioperative unit in which the multidisciplinary teams work, or off-site simulation (OSS), which is in dedicated simulation centres ${ }^{18,21}$. Conducting simulation training within the perioperative unit in which multidisciplinary team members work is believed to increase the authenticity and fidelity of the simulation training $39,45,46,50$. In a study conducted by S $\phi$ rensen ${ }^{39}$, multidisciplinary perioperative team members believed ISS training would increase fidelity, therefore resulting in increased participant engagement. However, other factors became more important in relation to simulation participants' 'buy in', for example, multidisciplinary team members deemed authentic roles and realistic teamwork to be more important than simulation location. Improvements in teamwork, communication and safety climate within the multidisciplinary perioperative teams did not differ between ISS and OSS even though ISS was seen to be more authentic and realistic than OSS ${ }^{59}$.

Conducting ISS training provides the opportunity for perioperative teams to identify latent safety threats within their clinical settings and identify changes which need to be made within organisations ${ }^{45,46,59}$. Shapiro ${ }^{46}$ used simulation training within their office-based plastic surgery clinic to not only improve the non-technical and technical skills of the staff but also test system issues within the office-based surgery. Furthermore, Shapiro ${ }^{46}$ used simulation training to ensure their office-based plastic surgery practice complied with the accreditation standards for officebased practices within the United States.

Organisational changes can also be identified through simulation training. Slightly more organisational changes were identified by multidisciplinary perioperative team members undertaking ISS than those who undertook OSS training ${ }^{59}$. However, perioperative team members undertaking oss found the location of training provided other unique learning opportunities ${ }^{39}$. Their ability to adapt was challenged during OSS and adaptation during emergency events was seen as an important skill to possess. Furthermore, participants found that they were able to examine their routines from 'the outside' giving them a new perspective on their practices. Despite this advantage, perioperative team members identified being unfamiliar with the simulation environment as a drawback. Their focus shifted from improving essential non-technical skills to physical activities, such as searching for drugs and equipment, which they did not consider to be a priority or effective for learning ${ }^{39}$.

\section{Clinical change}

\section{Patient safety}

Safe perioperative patient care is closely associated with effective communication and teamwork ${ }^{15,62,63}$. Hinde ${ }^{60}$ was able to show an improvement in safety climate following multidisciplinary simulation training due to improved teamwork, but stated that it was difficult to demonstrate a correlation between effective teamwork and improved safety culture and improved patient outcomes ${ }^{60}$. This is contrary to the findings presented by Weller ${ }^{38}$ and Weller ${ }^{42}$ who reported that an improvement in BMRI scores of 20 per cent correlated with a 14-16 per cent decrease in the likelihood of adverse events in the post-operative surgical patient ${ }^{38,42}$. Doumouras ${ }^{58}$ demonstrated that effective non-technical skills reduced the time to crisis resolution during surgical and anaesthetic emergencies. 
This highlights the importance for multidisciplinary perioperative teams to undertake simulation training to increase perioperative patient safety.

Patient safety can be further improved through multidisciplinary simulation training as multidisciplinary teams test organisational systems, identify latent safety threats and test clinical practices ${ }^{64}$. Following simulation training, Shapiro et al. ${ }^{46}$ increased their multidisciplinary staff members' awareness of safety issues and identified processes which needed to be changed to increase patient safety ${ }^{46}$. Similar results were demonstrated by Sфrensen ${ }^{39}$ and $S \phi r e n s e n^{59}$ who reported that multidisciplinary perioperative team members were able to identify changes which needed to be made within their organisation to improve patient safety ${ }^{39,59}$.

\section{Barriers to program implementation}

\section{Cost}

The development and implementation of simulationbased training programs can be costly ${ }^{25}$. Reported costs within the literature include $\$ 50000$ NZD for models and further costs of $\$ 4000$ NZD a day excluding staff wages paid during simulation training ${ }^{38}$. Paige ${ }^{43}$ estimated their costs to be $\$ 9400$ USD in total for the simulation session but they concede their cost estimates are low. Lost operating time, instructor training and instructor fees are not included in the estimates ${ }^{43}$. Given the substantial costs of simulation training, improvements in teamwork, communication and patient safety, such as those reported by Weller ${ }^{38}$ and Weller ${ }^{42}$, need to be demonstrated to gain support and funding from senior management and health care organisations ${ }^{38,42,44,45}$.
This provides evidence of improved patient outcomes which correlates with decreased health care costs, which can be used to gain support and possible funding from senior management and/or alternative funding sources $38,43-45$.

\section{Time}

A further barrier to implementing multidisciplinary simulation training is lack of time for facilitators to set up and run simulation training, and the lack of time to dedicate an entire operating theatre to simulation training ${ }^{45}$. Study participants reported they lacked the required time to set up simulation equipment and course material ${ }^{45}$. Furthermore, finding time between busy lists to set aside an operating theatre, resourcing facilitators and getting all team members together is challenging ${ }^{44,45}$. Wongsirimeteekul ${ }^{52}$ provided the schedule for simulation training months in advance to ensure they could secure nonclinical time for staff to participate in multidisciplinary simulation training. In contrast, Rochlen ${ }^{50}$ designed their simulation training so that it could be conducted within one hour, making it easier to fit in with preexisting weekly education and having minimal impact on operating times within the theatres. Integrating the multidisciplinary simulation training within existing education programs provides a way of negating the timebased barriers to implementation ${ }^{45,50}$.

\section{Further research}

Despite the impact negative hierarchies can have on the effective functioning of multidisciplinary perioperative teams, hierarchies are not discussed in detail within the literature and neither is assertiveness. Furthermore, the ability for lessons learnt to be transferred to the perioperative team as a whole when one or two disciplines undertook simulation training should be explored further. The largest gap in the literature, is the absence of Australian studies examining multidisciplinary simulation training for perioperative teams. It is unclear if simulation training is conducted regularly in Australian perioperative units and if there are positive or negative impacts on perioperative patient care. Further research involving multidisciplinary perioperative teams from Australian perioperative units should be conducted to gain a greater insight into multidisciplinary simulation training and the effects of such training before recommendations for practice changes can be made.

\section{Conclusion and recommendations}

Multidisciplinary simulation training undertaken by perioperative teams led to improvements in technical skills, non-technical skills and recognition of organisational changes, all of which improved perioperative patient safety. Individual non-technical skills such as communication were improved and techniques to improve communication were identified. Likewise, teamwork was also improved following simulation training. A high level of simulation fidelity is important for perioperative team members to engage in multidisciplinary simulation training and, initially, ISS was thought to be more beneficial than oss training. However, clinical and organisational changes were identified in both settings. Despite the numerous benefits of multidisciplinary simulation training, barriers to the implementation of such training programs exist. Multidisciplinary simulation training is costly to set up and time-consuming to conduct.

There were gaps identified within in the literature following this 
integrative review. Professional hierarchies and the lack of assertiveness within perioperative teams were not discussed in detail. There is also a lack of guidance on the frequency of simulation training and types of scenarios which should be used during simulation training. Lastly, none of the 14 primary studies used in this integrative review involve research conducted in Australia.

The perioperative environment is a dynamic and high-risk environment and requires multidisciplinary perioperative teams to engage in effective teamwork and communication. Although costly and time-consuming, simulation training improves both technical and non-technical skills within multidisciplinary perioperative teams increasing effective teamwork, communication and collaboration, and therefore improving perioperative patient safety. However, further research is required to discern the effects of multidisciplinary simulation training on Australian perioperative teams before further recommendations for clinical practice change can be made in the Australian context.

\section{References}

1. World Health Organization (WHO). Patient safety [Internet]. Geneva: WHO; 2020 [cited 2020 September 28]. Available from: www.who.int/patientsafety/safesurgery/en/.

2. Sutherland-Fraser S, Osborne S, Bryant K. Perioperative nursing. In: Hamlin L, Davies $M$, Richardson-Tench M, Sutherland-Fraser $S$, editors. Perioperative Nursing: An Introductory Text. Sydney: Elsevier; 2016, pp. 1-29.

3. Gillespie BM, Davies M. The perioperative team and interdisciplinary collaboration. In: Hamlin L, Davies M, Richardson-Tench M, Sutherland-Fraser S, editors. Perioperative Nursing: An Introductory Text. Sydney: Elsevier; 2016, pp. 30-46.

4. Wang R, Shi N, Bai J, Zheng Y, Zhao Y. Implementation and evaluation of an interprofessional simulation-based education program for undergraduate nursing students in operating room nursing education: A randomized controlled trial. BMC Med Educ 2015;15:115.
5. Ozawa E, Mahboobi S. Teamwork in the operating room. In: Paige J, Sonesh S, Garbee D, Bananno L, editors. Comprehensive Health Care Simulation: Interprofessional Team Training And Simulation. Cham, Switzerland: Springer Nature Switzerland AG; 2020, pp. 249-260.

6. Palaganas JC, Epps C, Raemer DB. A history of simulation-enhanced interprofessional education. J Interprof Care 2014;28(2):110-115.

7. Komasawa N, Berg BW. Interprofessional simulation training for perioperative management team development and patient safety. J Perioper Pract 2016;26(11):250-253.

8. Jowsey T, Beaver P, Long J, Civil I, Garden AL, Henderson $\mathrm{K}$ et al. Towards a safer culture: Implementing multidisciplinary simulationbased team training in New Zealand operating theatres - a framework analysis. BMJ Open 2019;9(10):e027122.

9. Teunissen C, Burrell B, Maskill V. Effective surgical teams: An integrative literature review. West J Nurs Res 2020;42(1):61-75.

10. Stephens T, Hunningher A, Mills $H$, Freeth D. An interprofessional training course in crises and human factors for perioperative teams. J Interprof Care 2016;30(5):685-688.

11. Tan SB, Pena G, Altree M, Maddern GJ. Multidisciplinary team simulation for the operating theatre: A review of the literature. ANZ J Surg. 2014;84(7-8):515-522.

12. Krage R, Erwteman M. State-of-the-art usage of simulation in anesthesia: Skills and teamwork. Curr Opin Anaesthesiol 2015;28(6):727-734.

13. Zhang C, Thompson S, Miller C. A review of simulation-based interprofessional education. Clin Simul Nurs 2011;7(4): e117-e126.

14. Coyle M, Martin D, McCutcheon K. Interprofessional simulation training in difficult airway management: A narrative review. Br J Nurs 2020;29(1):36-43.

15. Weller J, Long JA, Beaver P, Cumin D, Frampton C, Garden AL et al. Evaluation of the effect of multidisciplinary simulationbased team training on patients, staff and organisations: Protocol for a stepped-wedge cluster-mixed methods study of a national, insurer-funded initiative for surgical teams in New Zealand public hospitals. BMJ Open 2020;10(2):e032997.

16. Cain CL, Riess ML, Gettrust L, Novalija J. Malignant hyperthermia crisis: Optimizing patient outcomes through simulation and interdisciplinary collaboration. AORN J 2014;99(2):301-308.

17. Myatra S, Kalkundre R, Divatia J. Optimizing education in difficult airway management: Meeting the challenge. Curr Opin Anaesthesiol 2017;30(6):748-754.
18. Posner GD, Clark ML, Grant VJ. Simulation in the clinical setting: Towards a standard lexicon. Adv Sim 2017;2(1):1-5.

19. Singh D, Kojima T, Gurnaney $H$, Deutsch ES. Do fellows and faculty share the same perception of simulation fidelity? A pilot study. Simul Healthc 2020(4):266.

20. Sathiya Kumar R, Steven M, Salman N, Jørgen E, Per H. Impact of simulation fidelity on student self-efficacy and perceived skill development in maritime training. TransNav: International Journal on Marine Navigation and Safety of Sea Transportation. 2019;13(3):663-669.

21. Armenia S, Thangamathesvaran L, Caine $A D$, King $N$, Kunac A, Merchant AM. The role of high-fidelity team-based simulation in acute care settings: A systematic review. Surgery 2018;4(3):e136-e151.

22. Masiello I. Why simulation-based team training has not been used effectively and what can be done about it. Adv Health Sci Educ Theory Pract 2012;17(2):279-288.

23. Kasana R, Tachawan J, Pavinee S. Correlation of medical knowledge and non-technical skills assessment in anesthesia residents. Siriraj Med J 2020;72(6):483-487.

24. Henderson A. Communication for health care practice. Victoria: Oxford University Press; 2019.

25. Brunges M, Hughes TE. Using virtual human technology in perioperative team training simulations. AORN J 2020;111(6):617-626.

26. Altabbaa G, Kaba A, Beran TN. Moving on from structured communication to collaboration: A communication schema for interprofessional teams. J Healthc Commun 2019;12(3/4):160-169.

27. Foronda C, MacWilliams B, McArthur E. Interprofessional communication in health care: An integrative review. Nurse Educ Pract 2016;19:36-40

28. Peavey E, Cai H. A systems framework for understanding the environment's relation to clinical teamwork: A systematic literature review of empirical studies. Environ Behav 2020;52(7):726-760.

29. Noble H, Smith J. Reviewing the literature: Choosing a review design. Evid Based Nurs 2018;21(2):39-41.

30. Whitehead D. Critically searching and reviewing the literature. In: Whitehead D, Ferguson C, L'oBiondo-Wood G, Haber J, editors. Nursing and Midwifery Research Methods for Appraisal for Evidence-based Practice $6^{\text {th }}$ ed. Chatswood: Elsevier; 2020. pp. 55-80.

31. Bowling A. Research methods in health: Investigating health and health services. Maidenhead: Open University Press; 2014

32. Gerrish K, Lathlean J. The research process in nursing. Chichester: John Wiley \& Sons Inc.; 2015. 
33. Joanna Briggs Institute. Critical appraisal tools. Adelaide: Joanna Briggs Institute; 2020.

34. Joanna Briggs Institute. Checklist for quasiexperimental studies (non-randomised experimental studies). Adelaide: Joanna Briggs Institute; 2020.

35. Joanna Briggs Institute. Checklist for qualitative research. Adelaide: Joanna Briggs Institute; 2020.

36. Neville S, Whitehead D. Analysing data in qualitative research. In: Whitehead D, Ferguson C, LoBiondo-Wood G, Haber J, editors. Nursing and Midwifery Research Methods for Appraisal for Evidence-based Practice $6^{\text {th }}$ ed. Chatswood: Elsevier; 2020. pp. 136-155.

37. Diaz MCG, Dawson K. Impact of simulationbased closed-loop communication training on medical errors in a pediatric emergency department. Am J Med Qual 2020 Dec;35(6):474-478.

38. Weller J, Cumin D, Torrie J, Boyd M, Civil ID, Madell $D$ et al. Multidisciplinary operating room simulation-based team training to reduce treatment errors: A feasibility study in New Zealand hospitals. NZ Med J 2015;128(1418):40-51.

39. Sørensen JL, Navne LE, Emdal HM, Ottesen $\mathrm{B}$, Albrecthsen CK, Pedersen BW et al. Clarifying the learning experiences of health care professionals with in situ and off-site simulation-based medical education: A qualitative study. BMJ Open 2015;5(10):e008345.

40. Mohammed HME-HS, Badawy SSI, Hussien AlH, Gorgy AAF. Assessment of noise pollution and its effect on patients undergoing surgeries under regional anesthesia, is it time to incorporate noise monitoring to anesthesia monitors: An observational cohort study. Ain-Shams J Anesthesiol 2020;12(1):1-9.

41. Smith P, Gibbs J. 'Below ten thousand': An effective behavioural noise reduction strategy? JPN 2016;29(3):29-32.

42. Weller J, Cumin D, Civil ID, Torrie J, Garden A, MacCormick A et al. Improved scores for observed teamwork in the clinical environment following a multidisciplinary operating room simulation intervention. NZ Med J 2016;129(1439):59-67.

43. Paige JT, Garbee DD, Kozmenko V, Yu Q, Kozmenko L, Yang T et al. Getting a head start: High-fidelity, simulationbased operating room team training of interprofessional students. J Am Coll Surg 2014;218(1):140-149.

44. Weller J, Civil I, Torrie J, Cumin D, Garden A, Corter A et al. Can team training make surgery safer? Lessons for national implementation of a simulation-based programme. NZ Med J 2016;129(1443):917.
45. Long JA, Jowsey T, Henderson KM, Merry AF, Weller JM. Sustaining multidisciplinary team training in New Zealand hospitals: A qualitative study of a national simulationbased initiative. NZ Med J 2020;133(1516):1021.

46. Shapiro FE, Pawlowski JB, Rosenberg NM, Xiaoxia L, Feinstein DM, Urman RD. The use of in-situ simulation to improve safety in the plastic surgery office: A feasibility study. ePlasty 2014;14:620.

47. World Health Organization (WHO). WHO Surgical Safety Checklist Implementation [Internet]. Geneva: WHO;2020 [cited 2020 September 28]. Available from: www.who.int/patientsafety/safesurgery/ checklist_implementation/en/.

48. Gorman S, Cox T, Hart RS, Marais L, Wallis S, Ryan J et al. Who's who? Championing the '\#TheatreCapChallenge'. J Perioper Pract 2019;29(6):16671.

49. Burton ZA, Guerreiro F, Turner M, Hackett R. Mad as a hatter? Evaluating doctors' recall of names in theatres and attitudes towards adopting \#theatrecapchallenge. $\mathrm{Br}$ J Anaesth 2018;121(4):9846

50. Rochlen LR, Malloy KM, Chang H, Kim S, Guichard L, Cassidy R et al. Pilot one-hour multidisciplinary team training simulation intervention in the operating room improves team nontechnical skills. J Educ Perioper Med 2019;21(2):e624.

51. Kim Y-J, Yoo J-H. The utilization of debriefing for simulation in health care: A literature review. Nurse Educ Pract 2020 Feb;43.

52. Wongsirimeteekul P, Mai CL, Petrusa E, Minehart R, Hemingway M, PianSmith $M$ et al. Identifying and managing intraoperative arrhythmia: A multidisciplinary operating room team simulation case. MedEdPORTAL 2018 Feb;14:10688.

53. Arriaga AF, Gawande AA, Raemer DB, Jones $D B$, Smink DS, Weinstock $P$ et al. Pilot testing of a model for insurer-driven, large-scale multicenter simulation training for operating room teams. Ann Surg 2014;259(3):40310.

54. Tosterud R, Kjølberg K, Kongshaug AV, Haugom JV. Exploration of two different structures for debriefing in simulation: The influence of the structure on the facilitator role. Simul Gaming 2020;51(2):24357.

55. Leithead J, Garbee DD, Yu Q, Rusnak VV, Kiselov VJ, Zhu L et al. Examining interprofessional learning perceptions among students in a simulation-based operating room team training experience. J Interprof Care 2019;33(1):2631.

56. Bould MD, Sutherland S, Sydor DT, Naik $\mathrm{V}$, Friedman Z. Residents' reluctance to challenge negative hierarchy in the operating room: A qualitative study. Can J Anaes 2015;62(6):57686.
57. Broom J, Broom A. Fear and hierarchy: Critical influences on antibiotic decisionmaking in the operating theatre. J Hosp Infect 2017;99(2):1246

58. Doumouras AG, Hamidi M, Lung K, Tarola CL, Tsao MW, Scott JW et al. Non-technical skills of surgeons and anaesthetists in simulated operating theatre crises. Br J Surg 2017;104(8):102836.

59. Sфrensen JL, van der Vleuten C, Rosth $\varnothing \mathrm{j}$ S, Østergaard D, LeBlanc V, Johansen $M$ et al. Simulation-based multiprofessional obstetric anaesthesia training conducted in situ versus offsite leads to similar individual and team outcomes: A randomised educational trial. BMJ Open 2015;5(10):e008344

60. Hinde T, Gale T, Anderson I, Roberts $M$, Sice P. A study to assess the influence of interprofessional point of care simulation training on safety culture in the operating theatre environment of a university teaching hospital. J Interprof Care 2016;30(2):2513.

61. Murphy M, Curtis K, McCloughen A. What is the impact of multidisciplinary team simulation training on team performance and efficiency of patient care? An integrative review. AENJ 2016;19(1):4453.

62. Cumin D, Boyd MJ, Webster CS, Weller JM. A systematic review of simulation for multidisciplinary team training in operating rooms. Simul Healthc 2013;8(3):1719.

63. Rydenfält C, Borell J, Erlingsdottir G. What do doctors mean when they talk about teamwork? Possible implications for interprofessional care. J Interprof Care 2019;33(6):71423.

64. Lie SA, Wong LT, Chee M, Chong SY. Processoriented in situ simulation is a valuable tool to rapidly ensure operating room preparedness for COVID-19 outbreak. Simul Healthc 2020;15(4):22533. 